\title{
Erratum to: Large anisotropic negative thermal expansion in Cu-TDPAT metalorganic framework: A combined in situ X-ray diffraction and DRIFTS study
}

\author{
Mehrdad Asgari ${ }^{1}$, llia Kochetygov ${ }^{1}$, Hassan Abedini ${ }^{1,2}$, and Wendy L. Queen ${ }^{1}(\square)$ \\ ${ }^{1}$ Institut des Sciences et Ingénierie Chimiques, École Polytechnique Fédérale de Lausanne (EPFL) - Valais Wallis, CH-1951 Sion, Switzerland \\ ${ }^{2}$ Gas Engineering Department, Faculty of Petroleum, Petroleum University of Technology (PUT), Ahwaz 61991-71183, Iran \\ (C) Tsinghua University Press and Springer-Verlag GmbH Germany, part of Springer Nature 2020
}

\section{Erratum to}

Nano Research 2021, 14(2): 404-410

https://doi.org/10.1007/s12274-020-2792-y

The title of Ref. [19] in References in page 6 was unfortunately wrong,

\section{instead of}

Dry post-combustion $\mathrm{CO}_{2}$ capture: The effect of ligand properties on the efficiency of M-BTTri family of frameworks

It should read

Understanding how ligand functionalization influences $\mathrm{CO}_{2}$ and $\mathrm{N}_{2}$ adsorption in a sodalite metal-organic framework 